\title{
Correlation between diurnal variation of intraocular pressure, ocular pulse amplitude and corneal structural properties
}

\author{
Correlação entre a variação diurna da pressão intraocular, amplitude de pulso \\ e propriedades estruturais corneanas
}

\author{
Flávia Silva Villas-Bôas ${ }^{1}$ \\ Larissa Morimoto Doi ${ }^{2}$ \\ Aline Kátia Siqueira Sousa ${ }^{3}$ \\ Luiz Alberto S. Melo Jr. ${ }^{4}$
}

Trabalho realizado no Departamento de Oftalmologia da Universidade Federal de São Paulo - UNIFESP - São Paulo (SP) - Brasil.

${ }^{1}$ Médica Oftalmologista do Instituto Brasileiro de Oftalmologia e Prevenção à Cegueira.

${ }^{2}$ Pós-graduanda em Oftalmologia pela UNIFESP - São Paulo (SP) - Brasil.

${ }^{3}$ Estagiária em Glaucoma da UNIFESP - São Paulo (SP) - Brasil.

${ }^{4}$ Colaborador do Setor de Glaucoma do Departamento de Oftalmologia da UNIFESP - São Paulo (SP) - Brasil. Address for correspondence: Flávia da Silva VillasBôas. Rua Wanderley de Pinho, 655/201 - Salvador (BA) CEP 41815-270

E-mail: f-villasboas@bol.com.br

Recebido para publicação em 14.09.2008

Última versão recebida em 16.02.2009

Aprovação em 03.03.2009

\begin{tabular}{|l|}
\hline ABSTRACT \\
\hline Purpose: The purpose of this study was to evaluate the fluctuation of \\
intraocular pressure measurements obtained by Goldmann applanation \\
tonometry, dynamic contour tonometry, and corneal compensated \\
non-contact tonometry during office hours in glaucoma and healthy \\
participants. This study also aims at correlating the intraocular pressure \\
fluctuations with fluctuations of corneal hysteresis, central corneal \\
thickness, mean central corneal curvature and ocular pulse amplitude. \\
Methods: A total of 12 controls ( 24 eyes) and 21 patients (38 eyes) with \\
open-angle glaucoma were recruited. Intraocular pressure measured by \\
Goldmann applanation tonometry, dynamic contour tonometry and \\
corneal compensated non-contact tonometry, ocular pulse amplitude, \\
central corneal curvature and thickness, corneal hysteresis, and re- \\
sistance factor were obtained at intervals of 2 hours, between 9 AM and \\
5 PM. Results: Intraocular pressure fluctuated significantly throughout \\
the day in controls and glaucoma individuals with all tonometers \\
(P<0.001). There was no statistically significant variation in mean \\
corneal curvature (P=0.048 in controls; $\mathrm{P}=0.04$ in glaucomatous) or \\
hysteresis over time (P=0.12 in controls; $\mathrm{P}=0.36$ in glaucomatous). The \\
ocular pulse amplitude showed a significant diurnal fluctuation in both \\
groups (P<0.001). There was a significant correlation between the \\
intraocular pressure measured by dynamic contour tonometry and \\
ocular pulse amplitude (P<0.001). Conclusion: There was significant \\
intraocular pressure fluctuation over office hours on measurements \\
performed by Goldmann applanation tonometry, dynamic contour \\
tonometry, and corneal compensated non-contact tonometry in normal \\
and glaucoma individuals. Intraocular pressure varied independently \\
of corneal hysteresis, central corneal thickness, and central curvature \\
variation. However, there was significant correlation between ocular \\
pulse amplitude and intraocular pressure measurements performed by \\
dynamic contour tonometry.
\end{tabular}

Keywords: Intraocular pressure; Cornea/anatomy \& histology; Corneal topography; Glaucoma; Tonometry, ocular; Circadian rhythm

\section{INTRODUCTION}

Intraocular pressure (IOP) is one of the most significant risk factors for glaucoma and remains the only parameter for which treatment has been demonstrated to decrease the glaucomatous progression ${ }^{(1-2)}$. 
Goldmann applanation tonometry (GAT) is the "gold standard" method to obtain IOP. However, GAT can be influenced by factors related to the corneal properties, such as corneal curvature and central corneal thickness $(\mathrm{CCT})^{(3)}$. These findings have prompted the development of new instruments to adjust IOP measurements according to these properties, such as the dynamic contour tonometry (DCT) and the cornealcompensated ocular response analyzer intraocular pressure $(\text { ORAcc) })^{(4-6)}$.

The DCT is a nonapplanation contact tonometer supposed to measure IOP independently of CCT and corneal curvatu$\mathrm{re}^{(4)}$. The DCT also provides the ocular pulse amplitude (OPA), which has been pointed as an indirect indicator of choroidal perfusion and reflection of ocular blood flow corresponding to heart pulse as a function of time ${ }^{(5)}$.

The ORAcc is based on the principle that information on biomechanical properties can be extracted by monitoring and analyzing corneal behavior when this structure is submitted to a force induced by an air jet ${ }^{(6)}$. The applanation detection system monitors the cornea throughout the entire process, and two independent pressure values are derived from the inward and outward applanation events ${ }^{(6)}$. The difference between these two pressure values is called corneal hysteresis $(\mathrm{CH})^{(6)}$.

This study aimed at evaluating the fluctuation of IOP measurements perfomed by these new instruments through the office hours and correlated these measurements with the fluctuations of corneal structural properties $(\mathrm{CCT}, \mathrm{CH}$, corneal curvature) and ocular pulse amplitude.

\section{METHODS}

A total of 12 healthy volunteers ( 24 eyes) and 21 (38 eyes) patients with open-angle glaucoma gave their informed consent and the study was in accordance with the principles of the Declaration of Helsinki and it was approved by the Ethics Committee of the Federal University of São Paulo, Brazil.

The inclusion criteria for the normal group were: IOP below $21 \mathrm{mmHg}$ in more than one occasion performed by Goldmann tonometer (Haag-Streit, Koniz, Switzerland); visual acuity better than 20/40, and normal optic nerve appearance in the fundus biomicroscopy. The inclusion criteria for the glaucoma group were: bilateral POAG with untreated IOP higher than $21 \mathrm{mmHg}$ measured at two different occasions, a glaucomatous visual field based on a reliable standard automated perimetry; or Goldmann perimetry and typical glaucomatous optic disk changes. Patients who had undergone trabeculectomy were also included. The visual fields were classified by the Glaucoma Staging System Stage Definitions and Severity Criteria ${ }^{(7)}$.

The exclusion criteria for both groups included media opacities, significant corneal alterations, contact lens wear in the last three months and significant tear film abnormality. Participants that presented suspect optic disc appearance or any previous ocular surgery were excluded from the normal group. Participants that presented low tension, exfoliation, pigmen- tary or secondary glaucomas, any ocular surgery less than 3 months before enrollment; or inability to fixate at the target in the instruments used over the study were excluded from the glaucoma group.

It was considered typical glaucomatous optic disc alteration: the cup-disc ratio larger than 0.6 and the presence of at least one of these signs: localized nerve fiber layer defect, localized optic nerve rim thinning, parapapillary atrophy, retinal or optic disc hemorrhages, and cup-disc ratio assimetry higher than 0.3 between both eyes of the individual.

IOP measured by GAT, DCT and ORAcc, central corneal curvature, CCT, OPA and ocular hysteresis readings were taken at intervals of 2 hours, during the office hours, at 9 AM, $11 \mathrm{AM}, 1 \mathrm{PM}, 3 \mathrm{PM}$ and 5 PM.

The first exam performed in each session was the central corneal curvature using a keratometer model Eyesys 3.04 (Vistatek).

CCT was measured always 10 minutes before IOP measurements, using a handheld ultrasonic pachymeter (Corneo Gage Plus - Sonogage) after instilling one drop of the topical anaesthetic $0.5 \%$ proxymethacaine. The pachymeter probe was placed on the center of the cornea, and the mean of three readings was calculated for each eye.

IOP was obtained in random order by GAT, DCT and ORAcc with an interval of ten minutes between them. Two consecutive readings were taken for each tonometer per eye and the mean value was used for the analysis. A calibrated and a slit lamp mounted Goldmann tonometer was used for GAT. The corneal astigmatism was considered to adjust the GAT biprism position.

The dynamic contour tonometer (Pascal dynamic contour tonometer, SMT Swiss Microtechnology AG, Switzerland) was mounted on the GAT stand. The tip of this tonometer contacted the cornea and the correct positioning was indicated by an audible signal that changes in pitch with changes in IOP detected. The pressure signal was detected for a period of 7 seconds and the tip was lifted off the eye. The IOP was automatically calculated besides ocular pulse amplitude and the measurement's quality and these values were displayed on a screen. When the readings quality were worse than 4 , they were not included and the measure was retaken. The ocular pulse amplitude (OPA) readings were also recorded.

Non-contact tonometer IOP and hysteresis were measured using the ORA (Ocular Response Analyser, ORA, Reichert Inc, Depew, NY). The patients were asked for fixating at the target in the instrument. An air puff was jet and then a signal was sent to the ORA. The IOP, corneal resistance factor (CRF) and $\mathrm{CH}$ were recorded.

All measurements were taken by the same observer using different formularies for each measurement session to avoid possible bias related to knowing previous measurements.

\section{Statistical analysis}

Linear mixed models were used to evaluate the variation of IOP and corneal structural properties during the office hours 
and also to evaluate the correlation between them. The significance level was set at 0.01 , rather than 0.05 , in light of multiplicity of tests performed.

\section{RESULTS}

The normal group was composed of 12 healthy individuals with a mean (SD) age of 43.0 years (13.3). The median (range) visual acuity was $20 / 20(20 / 20$ to $20 / 25)$. The median (range) cup to disc ratio was 0.37 ( 0.2 to 0.5$)$, and the median (range) mean deviation perimetrical index $-1.54 \mathrm{~dB}$ (0.54 to -3.34).

The glaucoma group was composed of 21 individuals with a mean (SD) age of 64.6 years (11.1). The median (range) visual acuity was 20/40 (20/20 to count fingers at $50 \mathrm{~cm})$. The median (range) cup to disc ratio was 0.85 (0.6 to 1.0$)$, and the median (range) mean deviation perimetrical index $-14.56 \mathrm{~dB}(-1.27$ to -32.15). Regarding visual field defect, no patients presented minimal defect; 6 eyes had early defect; 7 eyes had moderate defect; 14 eyes had advanced defect; 14 eyes had severe defect and 6 eyes had end-stage disease. Nine patients (16 eyes) had previously undergone trabeculectomy.

\section{Intraocular pressure}

The GAT IOP changed significantly throughout the day in the control group $(\mathrm{P}<0.001)$ (Table 1$)$. In both groups, the maximum IOP was recorded at 9 AM with the mean (SD) of $13.6 \mathrm{mmHg}$ (2.4) for the control group and $12.5 \mathrm{mmHg}$ (2.9) in the glaucoma group (Tables 1 and 2).

Healthy individuals presented a mean (SD) DCT IOP of $15.3 \mathrm{mmHg}$ (2.5) in the first IOP measurement that decreased throughout the day $(\mathrm{P}<0.001)$ (Table 1$)$. Glaucoma individuals presented a statistically significantly fluctuation and the IOP DCT had a peak at 9 AM (mean [SD] $15.2 \mathrm{mmHg}$ [3.0]).

The fluctuation in ORAcc and in the Goldmann-correlated ocular response analyzer IOP (ORAg) also presented highest values at the first session and the changes throughout the day were statistically significant in both groups (Figure 1).

\section{Corneal properties}

The fluctuation in mean corneal curvature is showed in the superior graphics of figure 1 . There was no statistically significant variation over time either in control $(\mathrm{P}=0.048)$ or in glaucoma group ( $\mathrm{P}=0.04)$ (Tables 1 and 2 ).

There was a small but significant mean CCT increase throughout the day in the glaucoma group $(\mathrm{P}=0.003)$ but not in the control group $(\mathrm{P}=0.42)$. The mean ocular hysteresis showed a small fluctuation throughout the day, which was not statistically significant. The CRF also did not present a statistically significant fluctuation during the day.

\section{Ocular pulse amplitude}

The ocular pulse amplitude showed a small but significant diurnal fluctuation $(\mathrm{P}<0.001)$ in both groups, with a maximum mean at 9 AM: $2.5 \pm 0.9 \mathrm{mmHg}$ (controls) and $2.2 \pm 0.7 \mathrm{mmHg}$ (glaucomatous).

Among the IOP and corneal structural properties the only significant correlation was between the IOP measured by DCT and OPA measurements $(\mathrm{P}<0.001)$ as presented in table 3 .

\section{DISCUSSION}

This study aimed at correlating IOP measurements and corneal properties during office hours. Most previous studies evaluating IOP measurements and corneal structural properties had a cross-sectional design and the fluctuation throughout the day was not considered ${ }^{(6,8-9)}$. Also, none of them compared the results between glaucoma and healthy individuals.

IOP fluctuation was observed with the three types of tonometers in control and glaucoma individuals in this study. Diurnal variation in IOP measured by GAT was recognized in many studies $^{(10-12)}$. Most investigators found rhythmic pressure variation during the day, and the first hours of the morning has often been the time when higher values have been recor$\operatorname{ded}^{(13-14)}$. The present study showed similar results for GAT.

\begin{tabular}{|c|c|c|c|c|c|c|}
\hline \multirow[b]{2}{*}{ Variable } & \multicolumn{6}{|c|}{ Clock time } \\
\hline & $\begin{array}{c}9: 00 \text { AM } \\
\text { Mean (SD) }\end{array}$ & $\begin{array}{l}\text { 11:00 AM } \\
\text { Mean (SD) }\end{array}$ & $\begin{array}{c}\text { 1:00 PM } \\
\text { Mean (SD) }\end{array}$ & $\begin{array}{c}\text { 3:00 PM } \\
\text { Mean (SD) }\end{array}$ & $\begin{array}{c}\text { 5:00 PM } \\
\text { Mean (SD) }\end{array}$ & $P$ \\
\hline \multicolumn{7}{|l|}{ Intraocular pressure (mmHg) } \\
\hline Goldmann applanation tonometry & $13.60(2.4)$ & $13.20(2.6)$ & $12.70(2.8)$ & $12.60(2.9)$ & $12.30(2.8)$ & $<0.001$ \\
\hline Dynamic contour tonometry & $15.30(2.5)$ & $14.80(2.6)$ & $14.50(2.4)$ & $13.90(2.4)$ & $14.00(3.0)$ & $<0.001$ \\
\hline ORAg & $15.50(3.8)$ & $14.80(4.3)$ & $13.80(3.4)$ & $14.20(4.3)$ & $12.80(3.9)$ & $<0.001$ \\
\hline ORAcc & $16.20(3.6)$ & $15.00(4.0)$ & $14.00(2.4)$ & $14.50(3.7)$ & $13.10(3.3)$ & $<0.001$ \\
\hline Ocular pulse amplitude (mmHg) & $2.50(0.9)$ & $2.50(0.9)$ & $2.30(0.7)$ & $2.10(0.8)$ & $2.20(0.7)$ & $<0.001$ \\
\hline Corneal hysteresis $(\mathrm{mmHg})$ & $10.20(1.6)$ & $10.70(1.6)$ & $10.90(1.6)$ & $10.70(1.7)$ & $10.80(1.7)$ & 0.120 \\
\hline Corneal resistance factor $(\mathrm{mmHg})$ & $10.30(1.8)$ & $10.50(1.9)$ & $10.30(2.2)$ & $10.30(2.2)$ & $10.00(2.1)$ & 0.420 \\
\hline Central corneal thickness $(\mu \mathrm{m})$ & $529.00(45.4)$ & $527.80(43.5)$ & $531.30(41.2)$ & $532.50(39.3)$ & $530.60(39.1)$ & 0.420 \\
\hline Mean keratometry (Diopter) & $44.37(1.95)$ & $44.53(1.96)$ & $44.31(1.99)$ & $44.31(1.96)$ & $44.39(1.88)$ & 0.048 \\
\hline
\end{tabular}


Table 2. Variation of the intraocular and corneal structural properties measurements during office hours in the glaucoma group

\begin{tabular}{|c|c|c|c|c|c|c|}
\hline \multirow[b]{2}{*}{ Variable } & \multicolumn{5}{|c|}{ Clock time } & \multirow[b]{2}{*}{$\boldsymbol{P}$} \\
\hline & $\begin{array}{c}9: 00 \text { AM } \\
\text { Mean (SD) }\end{array}$ & $\begin{array}{l}\text { 11:00 AM } \\
\text { Mean (SD) }\end{array}$ & $\begin{array}{c}1: 00 \text { PM } \\
\text { Mean (SD) }\end{array}$ & $\begin{array}{c}\text { 3:00 PM } \\
\text { Mean (SD) }\end{array}$ & $\begin{array}{c}\text { 5:00 PM } \\
\text { Mean (SD) }\end{array}$ & \\
\hline \multicolumn{7}{|l|}{ Intraocular pressure (mmHg) } \\
\hline Goldmann applanation tonometry & $12.50(2.9)$ & $11.90(3.1)$ & $11.70(3.3)$ & $11.80(4.0)$ & $12.00(3.9)$ & 0.040 \\
\hline Dynamic contour tonometry & $15.20(3.0)$ & $15.10(3.2)$ & $14.40(3.5)$ & $14.70(3.4)$ & $15.00(3.4)$ & $<0.001$ \\
\hline ORAg & $14.30(3.6)$ & $13.90(4.2)$ & $12.70(3.8)$ & $13.20(4.4)$ & $14.20(4.9)$ & $<0.001$ \\
\hline ORAcc & $16.50(4.1)$ & $16.00(3.8)$ & $14.80(3.8)$ & $15.60(3.9)$ & $16.20(4.6)$ & $<0.001$ \\
\hline Ocular pulse amplitude $(\mathrm{mmHg})$ & $2.20(0.7)$ & $2.10(0.7)$ & $1.90(0.7)$ & $1.90(0.7)$ & $2.10(0.7)$ & $<0.001$ \\
\hline Corneal hysteresis $(\mathrm{mmHg})$ & $8.90(2.1)$ & $8.90(2.1)$ & $9.20(2.2)$ & $8.90(2.1)$ & $9.10(1.9)$ & 0.360 \\
\hline Corneal resistance factor $(\mathrm{mmHg})$ & $8.80(2.0)$ & $8.80(2.3)$ & $8.60(2.3)$ & $8.50(2.4)$ & $8.90(2.2)$ & 0.080 \\
\hline Central corneal thickness $(\mu \mathrm{m})$ & $514.80(41.3)$ & $517.30(40.6)$ & $518.70(44.9)$ & $521.60(45.2)$ & $526.80(48.3)$ & 0.003 \\
\hline Mean keratometry (Diopter) & $43.87(1.99)$ & $43.97(1.94)$ & $43.92(1.98)$ & $43.94(1.95)$ & $44.13(2.06)$ & 0.040 \\
\hline
\end{tabular}

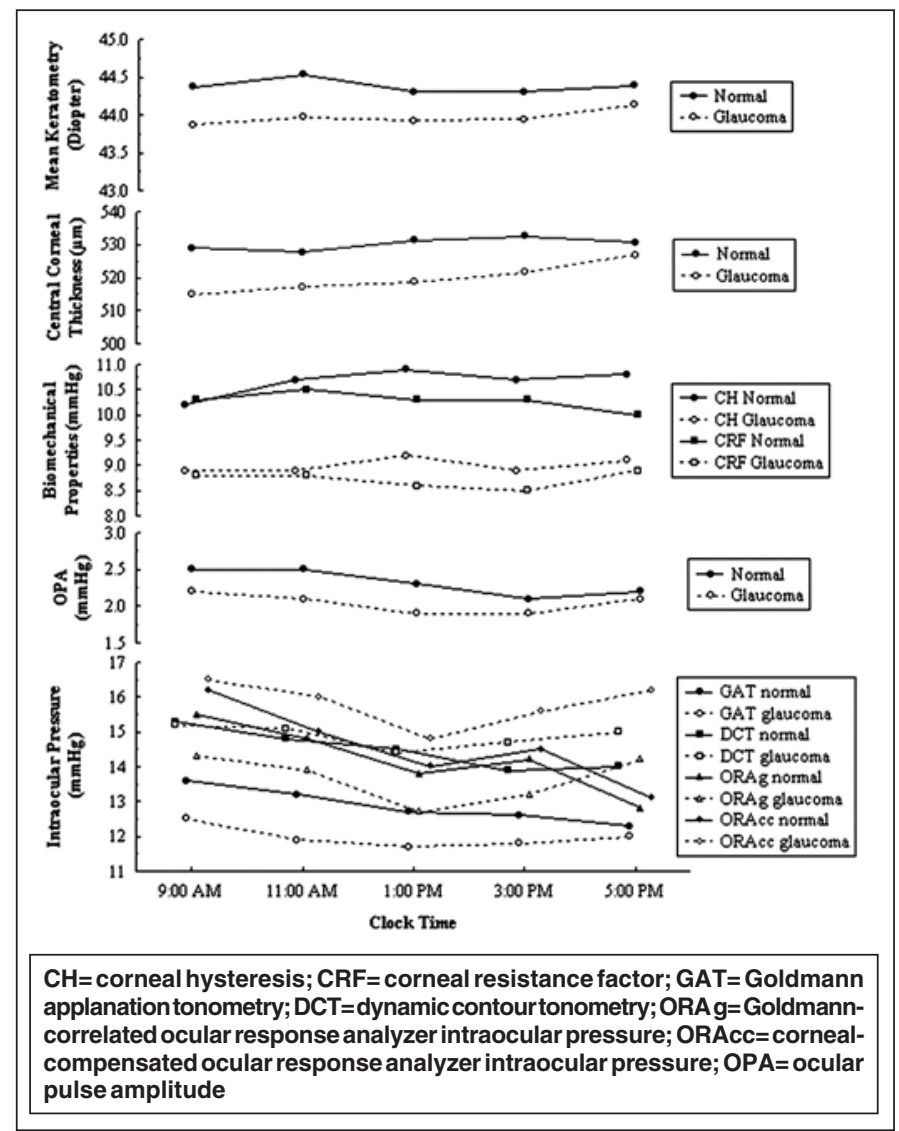

Figure 1 - Mean intraocular pressure, ocular pulse amplitude, and corneal structural properties during the office hours in the normal and glaucoma groups

Some studies evaluated the behavior of IOP measured over the day by $\mathrm{ORA}^{(15-17)}$. IOP fluctuation on ORA measurements was observed by some authors ${ }^{(18)}$. They showed a statistically significant difference of $1.6 \mathrm{mmHg}$ between the mean IOP measurement in the morning (8 AM) and late afternoon (5 PM). These results are in agreement with the present study, but the difference between the maximal and the minimal IOP measurement means in our study was $3.1 \mathrm{mmHg}$ in control group.

There are few studies evaluating the circadian variations in IOP measurements by DCT ${ }^{(19)}$. We recorded the IOP peak in the first morning measurement for both groups.

The glaucoma group showed smaller IOP fluctuation than the control group in all measurement methods used. This probably can be explained by the fact that most glaucoma patients were on treatment with antiglaucomatous medications and/or underwent antiglaucomatous surgery which probably contributed to decrease IOP fluctuation.

The OPA showed a small but statistically significant variation in control and glaucoma groups. Other study also found a significant fluctuation which was larger in patients with primary open angle glaucoma ${ }^{(19)}$.

The behavior of $\mathrm{CH}$ over 24-hours was already evaluated in 15 healthy volunteers, and the diurnal mean corneal hysteresis was $11.9 \pm 1.5 \mathrm{mmHg}^{(20)}$, not statistically different from the nocturnal mean corneal hysteresis of $11.7 \pm 1.9 \mathrm{mmHg}$. In our study, the fluctuation on corneal hysteresis was not significant either in glaucoma and normal groups.

Previous studies had reported CCT to be highest in the morning immediately after wakening and then to stabilize after approximately 1-2 hours ${ }^{(21)}$. However, this fluctuation was not statistically significant during office hours in some studies ${ }^{(2)}$, which suggests that a CCT single measurement in any office hour would be satisfactory. Lack of significant fluctuation was also found in the present study in the control group. However, in the glaucoma group, the CCT fluctuated during the office hours, which might be related to corneal alterations due to the antiglaucomatous medications.

The central corneal curvature showed a non significant fluctuation over the day in both groups. Other studies that analyzed the influence of corneal curvature on IOP measurements over 24 hour period reported no statistical change in central corneal curvature and no significant correlation between these variables ${ }^{(14)}$. 


\begin{tabular}{|c|c|c|c|c|}
\hline Response variable & Predictor variable & Regression coefficient & (99\% Confidence interval) & $\boldsymbol{P}$ \\
\hline GAT & $\mathrm{CH}$ & -0.090 & $(-0.390$ to 0.210$)$ & 0.440 \\
\hline $\mathrm{DCT}$ & $\mathrm{CH}$ & -0.190 & $(-0.490$ to 0.100$)$ & 0.090 \\
\hline GAT & CCT & 0.004 & $(-0.022$ to 0.031$)$ & 0.690 \\
\hline DCT & ССТ & 0.010 & $(-0.016$ to 0.036$)$ & 0.300 \\
\hline ORAg & СCT & 0.034 & $(-0.004$ to 0.073$)$ & 0.020 \\
\hline ORACC & CCT & 0.016 & $(-0.023$ to 0.055$)$ & 0.280 \\
\hline GAT & $\mathrm{KT}$ & 0.300 & $(-0.400$ to 0.990$)$ & 0.270 \\
\hline DCT & KT & 0.230 & $(-0.430$ to 0.890$)$ & 0.370 \\
\hline ORAg & KT & -0.100 & $(-1.140$ to 0.940$)$ & 0.800 \\
\hline ORACC & $\mathrm{KT}$ & 0.050 & $(-0.920$ to 1.030$)$ & 0.890 \\
\hline OPA & DCT & 0.210 & $(0.150$ to 0.260$)$ & $<0.001$ \\
\hline
\end{tabular}

Analyzing the studied variables, and IOP measured by the three tonometers, a significant correlation was found between OPA and IOP measured by DCT. For each $1 \mathrm{mmHg}$ IOP variation there was a $0.21 \mathrm{mmHg}$ OPA increase. In a cross-sectional study of 223 eyes in which CCT, corneal curvature, OPA measurements and other variables were correlated with DCT IOP measurements, a significant correlation between IOP and OPA was also found ${ }^{(23)}$. In that study, for each $1 \mathrm{mmHg}$ IOP variation there was a $0.12 \mathrm{mmHg}$ OPA increase ${ }^{(23)}$. However, measurements quality in DCT was not considered there ${ }^{(23)}$.

There was no correlation between IOP and CCT fluctuation in the present study. Some authors have concluded that the diurnal variation of CCT was too small to have a significant influence on IOP fluctuation ${ }^{(6,13,22)}$. Other study found a high correlation at $7 \mathrm{AM}$ between these two parameters, but there was not correlation after 9 AM, similar to our results ${ }^{(14)}$. The correlation between IOP variation and ocular hysteresis was not found in this and other studies ${ }^{(18,20)}$.

The limitations of our study include a relatively small sample size, and the measures were only evaluated during the office hours. Although corneal integrity was examined before and after each series of measurements, low grade superficial punctuate keratitis was observed in the corneal area in some participants, which was attributed to the toxicity of repeated doses of anesthetic, and desiccation after suppression of the blink reflex of the anesthetized eye. Six of the 21 glaucomatous and 3 of the 12 control participants were affected. The participants reported mild discomfort, but no vision loss was observed. This adverse event was also registered in a previous study that evaluated IOP and corneal structural properties over the day ${ }^{(14)}$.

\section{CONCLUSION}

There was significant IOP fluctuation over office hours on measurements performed by GAT, DCT, and ORAcc in normal and glaucoma individuals. In this study, IOP fluctuated independently of $\mathrm{CH}, \mathrm{CCT}$ and central curvature variation during office hours.
However, there was significant correlation between ocular pulse amplitude and IOP measurements performed by DCT.

\section{RESUMO}

Objetivo: Avaliar a flutuação das medidas da pressão intraocular obtidas pela tonometria de aplanação de Goldmann, tonometria de contorno dinâmico e pela tonometria de não-contato com compensação corneana durante o período ambulatorial, em participantes com glaucoma e saudáveis. Esse estudo também correlacionou as flutuações da pressão intraocular com as flutuações da histerese corneana, espessura corneana central, média da curvatura corneana central e amplitude de pulso ocular. Métodos: Um total de 12 controles ( 24 olhos) e 21 pacientes com glaucoma de ângulo aberto (38 olhos) foram selecionados. A pressão intraocular medida pela tonometria de aplanação de Goldmann, tonometria de contorno dinâmico e tonometria de não-contato com compensação corneana, amplitude de pulso ocular, a curvatura central e espessura corneanas, a histerese corneana e o fator de resistência foram medidos em intervalos de 2 horas, entre 9 AM e 5 PM. Resultados: A pressão intraocular flutuou significativamente durante o dia em indivíduos controles e com glaucoma em todos os tonômetros $(\mathrm{P}<0,001)$. Não houve variação estatisticamente significante na média da curvatura corneana central ( $\mathrm{P}=0,048$ em controles; $\mathrm{P}=0,04$ em glaucomatosos $)$ ou na histerese no período pesquisado $(\mathrm{P}=0,12$ em controles; $\mathrm{P}=0,36 \mathrm{em}$ glaucomatosos). A amplitude de pulso ocular mostrou uma flutuação diurna significativa em ambos os grupos $(\mathrm{P}<0,001)$. Houve uma correlação significante entre a pressão intraocular medida pela tonometria de contorno dinâmico e a amplitude de pulso ocular $(\mathrm{P}<0,001)$. Conclusão: Houve uma flutuação significante da pressão intraocular ao longo do período ambulatorial nas medidas realizadas pela tonometria de aplanação de Goldmann, tonometria de contorno dinâmico, e tonometria de não-contato com compensação corneana em indivíduos normais e com glaucoma. A pressão intraocular variou independente da variação da histerese, espessura e curvatura central corneanas. Entretanto, 
houve correlação significante entre a amplitude de pulso ocular e as medidas de pressão intraocular realizadas pela tonometria de contorno dinâmico.

Descritores: Pressão intraocular; Córnea/anatomia e histologia; Topografia da córnea; Glaucoma; Tonometria ocular; Ritmo circadiano

\section{REFERENCES}

1. Leske MC, Heijl A, Hussein M, Bengtsson B, Hyman L, Komaroff E; Early Manifest Glaucoma Trial Group. Factors for glaucoma progression and the effect of treatment: the early manifest glaucoma trial. Arch Ophthalmol. 2003;121(1): 48-56.

2. Kass MA, Heuer DK, Higginbotham EJ, Johnson CA, Keltner JL, Miller JP, et al. The Ocular Hypertension Treatment Study: a randomized trial determines that topical ocular hypotensive medication delays or prevents the onset of primary open-angle glaucoma. Arch Ophthalmol. 2002;120(6):701-13; discussion 829-30. Comment in: Arch Ophthalmol. 2003;121(7):1070; author reply 1070. Arch Ophthalmol. 2004;122(7):1088-9; author reply 1089.

3. Kohlhaas M, Boehm AG, Spoerl E, Pürsten A, Grein HJ, Pillunat LE. Effect of central corneal thickness, corneal curvature, and axial length on applanation tonometry. Arch Ophthalmol. 2006;124(4):471-6.

4. Punjabi OS, Kniestedt C, Stamper RL, Lin SC. Dynamic contour tonometry: principle and use. Clin Experiment Ophthalmol. 2006;34(9):837-40.

5. Hoffmann EM, Grus FH, Pfeiffer N. Intraocular pressure and ocular pulse amplitude using dynamic contour tonometry and contact lens tonometry. BMC Ophthalmol. 2004;23;4:4.

6. Medeiros FA, Weinreb RN. Evaluation of the influence of corneal biomechanical properties on intraocular pressure measurements using the ocular response analyzer. J Glaucoma. 2006;15(5):364-70.

7. Mills RP, Budenz DL, Lee PP, Noecker RJ, Walt JG, Siegartel LR, et al. Categorizing the stage of glaucoma from pre-diagnosis to end-stage disease. Am J Ophthalmol. 2006;141(1):24-30. Comment in: Am J Ophthalmol. 2006; 141(1):147-8; Am J Ophthalmol. 2006;141(6):1169-70; author reply 1170-1.

8. Martinez-de-la-Casa JM, Garcia-Feijoo J, Vico E, Fernandez-Vidal A, Benitez del Castillo JM, Wasfi M, et al. Effect of corneal thickness on dynamic contour, rebound, and Goldmann tonometry. Ophthalmology. 2006;113(12):2156-62.

9. Herndon LW. Measuring intraocular pressure-adjustments for corneal thickness and new technologies. Curr Opin Ophthalmol. 2006;17(2):115-9.
10. Pointer JS. The diurnal variation of intraocular pressure in non-glaucomatous subjects: relevance in a clinical context. Ophthalmic Physiol Opt. 1997;17(6): 456-65.

11. Shuba LM, Doan AP, Maley MK, Zimmerman MB, Dinn RB, Greenlee EC, et al. Diurnal fluctuation and concordance of intraocular pressure in glaucoma suspects and normal tension glaucoma patients. J Glaucoma. 2007;16(3):307-12.

12. Sihota R, Saxena R, Gogoi M, Sood A, Gulati V, Pandey RM. A comparison of the circadian rhythm of intraocular pressure in primary chronic angle closure glaucoma, primary open angle glaucoma and normal eyes. Indian J Ophthalmol. 2005;53(4):243-7.

13. Fogagnolo P, Rossetti L, Mazzolani F, Orzalesi N. Circadian variations in central corneal thickness and intraocular pressure in patients with glaucoma. $\mathrm{Br} \mathrm{J}$ Ophthalmol. 2006;90(1):24-8.

14. Hamilton KE, Pye DC, Aggarwala S, Evian S, Khosla J, Perera R. Diurnal variation of central corneal thickness and Goldmann applanation tonometry estimates of intraocular pressure. J Glaucoma. 2007;16(1):29-35.

15. Congdon NG, Broman AT, Bandeen-Roche K, Grover D, Quigley HA. Central corneal thickness and corneal hysteresis associated with glaucoma damage. Am J Ophthalmol. 2006;141(5):868-75.

16. Kotecha A, White ET, Shewry JM, Garway-Heath DF. The relative effects of corneal thickness and age on Goldmann applanation tonometry and dynamic contour tonometry. Br J Ophthalmol. 2005;89(12):1572-5.

17. Schneider E, Grehn F. Intraocular pressure measurement-comparison of dynamic contour tonometry and Goldmann applanation tonometry. J Glaucoma. 2006; 15(1):2-6. Comment in: J Glaucoma. 2006;15(5):471.

18. Laiquzzaman M, Bhojwani R, Cunliffe I, Shah S. Diurnal variation of ocular hysteresis in normal subjects: relevance in clinical context. Clin Experiment Ophthalmol. 2006;34(2):114-8. Comment in: Clin Experiment Ophthalmol. 2006;34(2):100-1.

19. Yun HM, Fu P, Yuan JS, Zhang B, Li XX. Diurnal variation curve of intraocular pressure and ocular pulse amplitude with dynamic contour tonometer in primary open-angle glaucoma and normal tension glaucoma patients. Zhonghua Yi Xue Za Zhi. 2006;86(48):3401-4.

20. Kida T, Liu JH, Weinreb RN. Effect of 24-hour corneal biomechanical changes on intraocular pressure measurement. Invest Ophthalmol Vis Sci. 2006;47(10): 4422-6.

21. du Toit R, Vega JA, Fonn D, Simpson T. Diurnal variation of corneal sensitivity and thickness. Cornea. 2003;22(3):205-9.

22. Shah S, Spedding C, Bhojwani R, Kwartz J, Henson D, McLeod D. Assessment of the diurnal variation in central corneal thickness and intraocular pressure for patients with suspected glaucoma. Ophthalmology. 2000;107(6):1191-3.

23. Kaufmann C, Bachmann LM, Robert YC, Thiel MA. Ocular pulse amplitude in healthy subjects as measured by dynamic contour tonometry. Arch Ophthalmol. 2006;124(8):1104-8. 